\title{
A Simple One-Pot Dehydration Process to Convert $N$-acetyl-D-glucosamine into a Nitrogen-Containing Compound, 3-acetamido-5-acetylfuran
}

Khaled W. Omari, Linda Dodot and Francesca M. Kerton*[a]

[a] K. W. Omari, L. Dodot, Prof. F. M. Kerton

Centre for Green Chemistry and Catalysis

Department of Chemistry

Memorial Iniversity of Newfoundland

St. John's, Newfoundland and Labrador, Canada A1B 3X7

Fax: (+) 17098643702

Tel: (+) 17098648089

E-mail: fkerton@mun.ca

Homepage: http://www.chem.mun.ca/zfac/fmk.php

Supporting information for this article is available on the WWW under http://www.chemsuschem.org or from the author.

This is a postprint version of the article. Please cite as follows:

K. W. Omari, J. E. Besaw and F. M. Kerton, Green Chem., 2012, 14, 1480.

http://dx.doi.org/10.1002/cssc.201200113

\section{Abstract}

An efficient process for converting N-acetyglucosamine (NAG) into 3-acetamido5-acetylfuran (3A5AF) is reported. $3 \mathrm{~A} 5 \mathrm{AF}$ is proposed as a $\mathrm{N}$-containing

platform chemical, which contains renewable nitrogen. In the reported method, NAG in the presence of boric acid $\left(\mathrm{B}(\mathrm{OH})_{3}\right)$ and sodium chloride $(\mathrm{NaCl})$ produces $58 \%$ yield $3 \mathrm{~A} 5 \mathrm{AF}$ in dimethylacetamide (DMA) under microwave irradiation $\left(220^{\circ} \mathrm{C}, 15 \mathrm{~min}\right)$. A maximum yield of $62 \%$ was obtained in the presence of 4 equiv $\mathrm{NaCl}$. Performing ICP-MS analysis on NAG from different chemical suppliers highlighted the importance of $\mathrm{Cl}$ and $\mathrm{B}$ levels in this process. Trace impurities are therefore important considerations in biomass transformations. This solution-phase process produces approximately 30 times more 3A5AF than via a previously reported pyrolysis route. 


\section{Introduction}

Renewable, bio-sourced feedstocks are now being widely studied for the production of both fuels and chemical precursors. ${ }^{[1-3]}$ These processes typically afford chemicals containing only $\mathrm{C}, \mathrm{H}$ and $\mathrm{O}$. There is growing interest in the production of renewable chemicals that contain other heteroatoms. For example, recently, caprolactam has been prepared in a four-step process from 5hydroxymethylfurfural (5-HMF) and ammonia. ${ }^{[4]}$ Inspired by such research, we wondered whether amino-sugars could be used as precursors to new $\mathrm{N}$ containing platform chemicals. Our initial studies in this area are presented herein.

$N$-acetyl-D-glucosamine (NAG), Figure 1a, is an amino sugar and also known as $\mathrm{N}$-acetyl-2-amino-2-deoxy-D-glucose. Chitin is a polysaccharide made up of NAG monomers. It is available from crustaceans' shells such as crab, lobster and shrimp (fisheries' waste). It is also found in the cell walls of fungi and insects. ${ }^{[5]}$ Chitin is produced on a large scale annually from a range of sources, ${ }^{[6]}$ and is the second most abundant biopolymer after cellulose. It is readily available, nontoxic and environmentally benign. Also, it may be available as a feedstock in regions of the world that do not have easy access to waste cellulosic biomass feed. Partial hydrolysis of chitin in $\mathrm{HCl}$ followed by neutralization, filtration, decolorization and salt removal affords 13.5 wt\% NAG. ${ }^{[7]}$ Chitin hydrolysis using enzymes is another approach to produce NAG e.g. cellulase has been used to produce $40 \mathrm{wt} \%$ NAG from chitin. ${ }^{[8]}$ Chitosan is the partially deacetylated form of chitin, which is also non-toxic and readily available. Hydrolysis of chitosan $(22 \%$ deacetylated) using hemicellulase can produce $6.5 \mathrm{wt} \%$ of NAG. [5] Two studies have been reported where NAG has been used as the starting material to yield low molecular weight organic products through decomposition pathways. Franich et al. produced 3-acetamido-5-acetylfuran (3A5AF), Figure 1b, from NAG. The pyrolysis of NAG was performed in a glass tube apparatus, which was heated in an oven at $400{ }^{\circ} \mathrm{C}$. The yield of $3 \mathrm{~A} 5 \mathrm{AF}$ obtained through this process was $2 \%,{ }^{[9]}$ which is currently the highest reported in the literature. In another study, NAG was mixed with anhydrous disodium hydrogen phosphate and quartz sand in a stainless steel vessel. The pyrolysis of this mixture was performed in an 
oil bath at $200{ }^{\circ} \mathrm{C}$ for $30 \mathrm{~min}$. After work-up, the major product was $3 \mathrm{~A} 5 \mathrm{AF}$ $(0.04 \%$ yield).[10] In our study, we present a novel method to produce $3 \mathrm{~A} 5 \mathrm{AF}$ from NAG using microwave irradiation to heat up the reaction mixture and also there is no need to adjust the $\mathrm{pH}$ of the mixture prior to extracting the $3 \mathrm{~A} 5 \mathrm{AF}$. The extraction procedure is performed using ethyl acetate, which is more environmentally friendly than chloroform, methanol and dichloromethane that were used in previous studies.[11]

The method reported herein produces 30 times the yield of the Franich et al. procedure. This novel process will allow 3A5AF to become available as a starting material for more complex chemical products. For example, polyamides proximicins A, B and C, Figure 2, are naturally occurring compounds, which have been isolated from marine actinomycete of the genus Verrucosispora.[12] Recently, proximicins A-C were studied as antitumor and antibiotic drugs.[13] Due to the similarity in structure between our furan product and sub-units in proximicins, we propose that NAG or other amino-sugars are the biosynthetic precursors to such complex natural products.

\section{Results and Discussion}

\section{Solvent screening}

At the beginning of this study, dimethylformamide (DMF) was used as a solvent in this process. The reaction mixture (50 mg NAG and $2 \mathrm{~mL} \mathrm{DMF}$ ) was microwave heated at $207^{\circ} \mathrm{C}$ for $15 \mathrm{~min}$. This temperature was selected based on the maximum safe working temperature for microwave-heating acetonitrile in our instrument. Acetonitrile was one of the screened solvents. The \%yield of $3 \mathrm{~A} 5 \mathrm{AF}$ that was produced from this reaction using DMF was the best among the solvents studied, Figure S1. We examined different solvents hoping to replace DMF with a greener solvent and produce more 3A5AF. The selected solvents have different "greenness", some of them have few and some have major environmental, health and safety issues associated with them.[14] TBME, CPME, DEA and EG did not yield any 3A5AF. Figure S1 shows that in ester solvents (TBOAc, IPOAc and EtOAc) small amounts of 3A5AF were produced (average $1.7 \%$ ) but in the related solvent EL 6.3\% was obtained. Interestingly, 3A5AF did not form in EG, but 8.1\% yield 3A5AF was produced in PEG. However, overall 
with respect to product yield, dipolar aprotic solvents (DMF, NMP, $\mathrm{CH}_{3} \mathrm{CN}$ and DMSO) performed the best with $24.6 \%$ yield of 3A5AF produced in DMF. Clearly, in order to produce a significant quantity of 3A5AF under the conditions studies, a dipolar aprotic solvent is required. Dimethylacetamide (DMA) is less dangerous than DMF, in terms of physical properties including boiling point, flashpoint and acute toxicity. Therefore, DMA was used and a yield of 31.3\% was obtained. This yield was ca. 15 times greater than the amount produced via pyrolysis reported in the literature. Unfortunately, we were unable to find any correlation between solvent polarity (and other solvent parameters) and the yields obtained in this solvent-screening study. However, it should be noted that no catalyst or other additive was used in these initial experiments.

\section{Catalyst/additive screening}

After determining that DMA will be the best solvent to use, we then attempted to find the best catalyst or additive, Table 1 . The reaction mixtures consisted of 10 $\mathrm{wt} \% \mathrm{NAG}$ of the total reaction mass and $6 \mathrm{~mol} \%$ catalyst. In the case of reactions in the presence of $\mathrm{LiBr}$, it was added at $10 \mathrm{wt} \%$ of the total mass. $\mathrm{LiBr}$ was added because bromide is a good nucleophile that has been shown to interact with glucose and fructose in DMA to increase the productivity of 5-HMF.[15] Table 1 shows that in presence of $\mathrm{LiBr}$, the \%yield $3 \mathrm{~A} 5 \mathrm{AF}$ is reduced. This contrasts with results using glucose and fructose. ${ }^{[15]} \mathrm{CrCl}_{3}$ has been shown to facilitate the isomerization of glucose into fructose to produce a high yield of 5-HMF.[16] $\mathrm{CrCl}_{3}$ has also been used in the conversion of cellulose into levulinic acid.[17] Therefore, it was tested in this study but failed to significantly increase the yield (entries 3 and 4). This might be due to strong nitrogen coordination (from the reagent, product or intermediate) to the chromium centre preventing catalytic turnover. The best catalysts were basic ones (entries 6-11). Despite $\mathrm{NH}_{3}$ not giving the best results in the screening, it was selected to study via factorial design for optimizing the method because it is cheap and relatively benign.

\section{Factorial Design (FD)}

Although studying one factor at a time to optimize reaction conditions is a common approach, it has some limitations such as neglecting the interaction 
between factors. Using FD, a researcher can study not only one factor at a time but also the effects of factors' interactions on the result.[18] Therefore, we studied the effects of five factors with each factor at two levels. These factors were NAG, DMA, amount of ammonia, temperature and time. The factors and levels are shown in table S1. The maximum \%yield of 3A5AF obtained was $42.6 \%$. This yield was achieved using $0.2356 \mathrm{~g}$ NAG, $4.5 \mathrm{~mL} \mathrm{DMA}, 0.26 \mathrm{mmol} \mathrm{NH}_{3}, 217^{\circ} \mathrm{C}$ and $15 \mathrm{~min}$. The results in this table were analyzed using Minitab software. The normal plot of the effects (Figure 3) shows that all effects are significant. In fact, in this case the individual effects (i.e. each factor alone) are more significant than combined effects/factors.

We tested the most significant effects at different levels, e.g. increased T, Figure S2, but none of these improved on the amount of 3A5AF produced (42.6\%) during the FD experiments.

\section{Testing NAG from different chemical suppliers}

The results described above were obtained using NAG purchased from Toronto Research Chemicals (TRC). When NAG from AK Scientific or Alfa Aesar was used, we were disappointed to obtain yields of $14.7 \%$ and $6.2 \%$, respectively. The challenge that faced us was to answer the following question; why did changing the supplier/source of NAG cause such a dramatic decrease in yield? After studying the impurity levels in the NAG from each supplier using ICP-MS, boron (B) and chloride $(\mathrm{Cl})$ concentrations stood out as being significantly higher in the NAG from TRC, Table 2.

\begin{tabular}{|lll|}
\hline \multicolumn{3}{l}{ Table 2. ICP-MS analyses for $\mathrm{B}$ and $\mathrm{Cl}$ in } \\
NAG from three suppliers. \\
\begin{tabular}{lll} 
Chemical & $\mathrm{B}[\mathrm{a}]$ & $\mathrm{Cl}[\mathrm{a}]$ \\
Supplier & & \\
\hline TRC & 27.9 & 20681 \\
AK Scientific & 4.4 & 819 \\
Alfa Aesar & 0.3 & 391 \\
\hline [a] mg B or Cl per Kg NAG
\end{tabular} \\
\hline
\end{tabular}


$\mathrm{Cl}^{-}$ions have been shown to have a significant and positive effect on biomass conversions processes ${ }^{[15,17,20]}$ Therefore, different amounts of $\mathrm{NaCl}$ were added to reaction mixtures to test the effect of $\mathrm{Cl}^{-}$concentration on 3A5AF production using NAG from AK Scientific and Alfa Aesar. Figure 4 shows that $\mathrm{NaCl}$ at 30-50 mol\% with respect to NAG produced the highest $\%$ yield of $3 \mathrm{~A} 5 \mathrm{AF}$.

NAG from Alfa Aesar consistently produced less 3A5AF compared with AK Scientific and we propose that this is because it contains less boron (see Table 2). Therefore, boron was added to the reaction mixture in the form of boric acid $\left(\mathrm{B}(\mathrm{OH})_{3}\right) . \mathrm{B}(\mathrm{OH})_{3}$ is a weak acid, non-toxic, inexpensive and readily available. Boric acid with $\mathrm{NaCl}$ has been used previously to increase 5-HMF production from hexoses. ${ }^{[19,20]}$ Yields of up to $42 \%$ from glucose and as much as $66 \%$ from sucrose have been reported.

Figure 5 shows the effect of adding $\mathrm{B}(\mathrm{OH})_{3}$ at a 2:1 $\mathrm{B}(\mathrm{OH})_{3}: \mathrm{NAG}$ mol ratio on $3 \mathrm{~A} 5 \mathrm{AF}$ production in the presence and absence of $\mathrm{NaCl}$ (30 mol\% with respect to NAG), and in the presence and absence of ammonia ( $24.4 \mathrm{~mol} \%$ of NAG). In all example reactions, Figure 5, the NAG from AK scientific produced more 3A5AF, which we propose is because of its initially higher $\mathrm{B}$ and $\mathrm{Cl}$ content, Table 2. Figure 5 emphasizes the significance of adding $\mathrm{Cl}^{-}$to the reaction mixture. The importance of $\mathrm{B}(\mathrm{OH})_{3}$ and $\mathrm{NaCl}$ in dehydrating $\mathrm{NAG}$ led us to study $3^{2} \mathrm{FD}$ to determine the optimum amounts that should be added. Table S2 shows $3^{2} \mathrm{FD}$ using $\mathrm{NaCl}$ at three levels 10,30 and $60 \mathrm{~mol} \%$ with respect to $\mathrm{NAG}$ and $\mathrm{B}(\mathrm{OH})_{3}$ at $0.5: 1,1: 1,2: 1$ mole ratios with respect to NAG. The other parameters for the reactions were kept constant at $0.2356 \mathrm{~g} \mathrm{NAG}, 4.5 \mathrm{~mL} \mathrm{DMA}, 220^{\circ} \mathrm{C}$ and $15 \mathrm{~min}$. The results were analyzed using Minitab software. The interaction plot for 3A5AF (Figure S3) shows that at each level of $\mathrm{B}(\mathrm{OH})_{3}$ the amount of $3 \mathrm{~A} 5 \mathrm{AF}$ produced increased with increasing $\mathrm{NaCl}$ concentration. The interaction plot also clearly shows that a 1:1 mole ratio of $\mathrm{B}(\mathrm{OH})_{3}: \mathrm{NAG}$ produced the highest yield of 3A5AF.

Figure 6 shows the \%yields of 3A5AF at different $\mathrm{NaCl}$ levels using a fixed amount of $1: 1 \mathrm{~B}(\mathrm{OH})_{3}: \mathrm{NAG}$ (mol ratio). $57.7 \%$ yield $3 \mathrm{~A} 5 \mathrm{AF}$ was produced at 2:1 $\mathrm{NaCl}$ NAG mol ratio in $15 \mathrm{~min}$. This compares well with studies using fructose and glucose, which produce 5-HMF. Using $\mathrm{NaCl}$ and $\mathrm{B}(\mathrm{OH})_{3}$, fructose has been shown to produce $60 \%$ yield 5-HMF and glucose produced $14 \%$ yield 5-HMF.[20] 
Therefore, at the present time, we assume that the reaction mechanism is similar to those reported for conventional carbohydrates.

Different Cl- sources were tested $\left(\mathrm{SnCl}_{4} .5 \mathrm{H}_{2} \mathrm{O}, \mathrm{MnCl}_{2} .4 \mathrm{H}_{2} \mathrm{O}, \mathrm{MgCl}_{2} \cdot 6 \mathrm{H}_{2} \mathrm{O}, \mathrm{KCl}\right.$, $\mathrm{CaCl}_{2} .2 \mathrm{H}_{2} \mathrm{O}, \mathrm{CaCl}_{2}, \mathrm{NaCl}$ and $\mathrm{LiCl}$ ) Figure $7 . \mathrm{NaCl}$ is the most benign and the cheapest chemical among them. Compared with $\mathrm{NaCl}$ (57.7\% yield), every chemical produced less $3 \mathrm{~A} 5 \mathrm{AF}$ except $\mathrm{LiCl}$, which produced $59.2 \%$ yield. DMA$\mathrm{LiCl}(10 \%)$ as a solvent in the presence of $\mathrm{CuCl}$ and 1-ethyl-3-methylimidazolium chloride ([EMIm]Cl) has been shown to produce 83\% yield 5-HMF from fructose.[15] $\mathrm{CaCl}_{2}$ produced $54.5 \%$ yield $3 \mathrm{~A} 5 \mathrm{AF}$ and $\mathrm{CaCl}_{2} .2 \mathrm{H}_{2} \mathrm{O} 50.7 \%$ yield, which shows that unfortunately water inhibits the production of $3 \mathrm{~A} 5 \mathrm{AF}$ in our system. In order to further study the effect of adding water to the reaction, several amounts of water were added $(1,2,4,6,8,10,15$ and $20 \% \mathrm{v} / \mathrm{v}$ in $4.5 \mathrm{~mL}$ DMA). Figure 44 shows that the \%yield of 3A5AF produced decreases as the amount of added water increases and is further evidence for water inhibiting this process. If dry, distilled DMA was used in reactions, no significant increase in 3A5AF yield was observed.

The effect of time on the reaction was studied at $0,5,10,15,30,45,60,75,90$ min. Figure S5 shows an approximately linear increase in 3A5AF production between 0 and 15 min but the amount of 3A5AF does not change significantly between 15 and $45 \mathrm{~min}$. However, the \%yield starts to decrease after $45 \mathrm{~min}$, which is probably due to thermal decomposition of 3A5AF. The effect of temperature on the reaction was studied by performing reactions at 160,180 , $200,220,240$ and $250^{\circ} \mathrm{C}$ for $15 \mathrm{~min}$, Figure 8 . It should be noted that temperature monitoring in commercial microwave instruments is not always accurate and care must be taken to ensure that the instrument is calibrated at regular intervals. The amount of 3A5AF produced increased linearly between 160 and $220^{\circ} \mathrm{C}$. Above $220^{\circ} \mathrm{C}, 3 \mathrm{~A} 5 \mathrm{AF}$ \%yield decreased presumably due to product decomposition. However, decomposition products were not observed in the chromatograms from these reactions and, therefore, the by-products are likely insoluble in ethyl acetate (Figure S6).

Preliminary studies towards scaling up the reaction were performed in a $300 \mathrm{~mL}$ autoclave (Parr ${ }^{\circledR}$ reactor 5500 series). The following conditions were used: 5.00 g NAG, $2.67 \mathrm{~g} \mathrm{NaCl}, 1.40 \mathrm{~g} \mathrm{~B}(\mathrm{OH})_{3}, 100 \mathrm{~mL} \mathrm{DMA}, 220^{\circ} \mathrm{C}, 15 \mathrm{~min}$. It should be 
noted that it took $30 \mathrm{~min}$ to achieve the desired reaction temperature and that the pressure at $220^{\circ} \mathrm{C}$ was approximately 6 bar. Under these reaction conditions, $42.8 \%$ yield of 3A5AF was obtained. Further studies are needed to optimize scale-up of this reaction.

\section{Conclusions}

Figure 9 shows the optimum reaction conditions that produce $58 \%$ yield $3 \mathrm{~A} 5 \mathrm{AF}$ from NAG. This is 30 times more $3 \mathrm{~A} 5 \mathrm{AF}$ than produced using previously reported pyrolysis methods. $\mathrm{NaCl}$ and $\mathrm{B}(\mathrm{OH})_{3}$ are very important additives in this reaction and markedly increase $3 \mathrm{~A} 5 \mathrm{AF}$ production. This study will allow the chemistry of 3A5AF, a carbohydrate-derived amide, to be studied further and it may find use either as a platform chemical, a source of renewable amines or as a high-value precursor to proximicins and other biologically active compounds. Some possible reactions of $3 \mathrm{~A} 5 \mathrm{AF}$ are shown in Figure 10. Due to the multifunctional nature of this compound (amide and ketone groups), selective transformations will be challenging but would also provide many opportunities for accessing a wide range of products.

In addition to looking at the reactivity of this compound, future studies will involve investigating the kinetics of this reaction, further scale-up studies and attempting to find (i) a more environmentally benign solvent to use and (ii) ways to re-use the $\mathrm{NaCl}$ and $\mathrm{B}(\mathrm{OH})_{3}$ components.

\section{Acknowledgements}

Research \& Development Corporation (RDC) of Newfoundland and Labrador Ocean Industries Award (KO), DAAD RISE worldwide internship (LD), NSERC of Canada and CFI (FK).

Keywords: Biomass · Amines · Carbohydrates · Catalysis

\section{References}

[1] J. J. Bozell, G. R. Petersen, Green Chem. 2010, 12, 539-554. 
[2] P. N. R. Vennestrøm, C. M. Osmundsen, C. H. Christensen, E. Taarning, Angew. Chem. 2011, 123, 10686-10694; Angew. Chem. Int. Ed. 2011, 50, 1050210509.

[3] Introduction to chemicals from biomass (Eds.: J. H. Clark, F. E. I. Deswarte), John Wiley \& Sons, Chichester, 2008

[4] T. Buntara, S. Noel, P. H. Phua, I. Melián-Cabrera, J. G. de Vries, H. J. Heeres, Angew. Chem. 2011, 123, 7221-7225; Angew. Chem. Int. Ed. 2011, 50, 70837087.

[5] R. A. A. Muzzarelli, M. G. Peter, Chitin Handbook, European Chitin Society, Grottammare, Italy, 1997.

[6] Y. Xu, C. Gallert, J. Winter, Appl. Microbiol. Biotechnol. 2008, 79, 687-697.

[7] S. Sato, K. Minamikawa (Nankai Kagaku Kogyo K. K., Japan). Process for the preparation of natural $N$-acetylglucosamine. JP 2009191001, August 27, 2009.

[8] H. Zhu, E. Muraki, S. Aiba. Book of Abstracts, 219th ACS National Meeting, San Francisco, CA, March 26-30, 2000, 69CLAC.

[9] R. A. Franich, S. J. Goodin, J. Anal. Appl. Pyrolysis 1984, 7, 91-100.

[10] J. Chen, M. Wang, C. Ho, J. Agric. Food Chem. 1998, 46, 3207-3209.

[11] F. M. Kerton, Alternative Solvents for Green Chemistry, RSC Publishing, Cambridge, 2009.

[12] F. E. Wolter, K. Schneider, B. P. Davies, E. R. Socher, G. Nicholson, O. Seitz, R. D. Süssmuth, Org. Lett. 2009, 11, 2804-2807.

[13] K. Schneider, S. Keller, F. E. Wolter, L. Röglin, W. Beil, O.Seitz, G. Nicholson, C. Bruntner, J. Riedlinger, H. Fiedler, R. D. Süssmuth, Angew. Chem. 2008, 120, 3302-3305; Angew. Chem. Int. Ed. 2008, 47, 3258-3261.

[14] R. K. Henderson, C. Jimenez-Gonzalez, D. J. C. Constable, S. R. Alston, G. G. A. Inglis, G. Fisher, J. Sherwood, S. P. Binks, A. D. Curzons, Green Chem. 2011, 13, 854-862.

[15] J. B. Binder, R. T. Raines, J. Am. Chem. Soc. 2009, 131, 1979-1985.

[16] H. Zhao, J. E. Holladay, H. Brown, Z. C. Zhang, Science 2007, 316, 15971600

[17] J. Potvin, E. Sorlien, J. Hegner, B. DeBoef, B. L. Lucht, Tetrahedron Lett. 2011, 52, 5891-5893. 
[18] D.C. Montgomery, Design and Analysis of Experiments, John Wiley \& Sons, Hoboken, NJ, 2009.

[19] T. Ståhlberg, S. Rodriguez-Rodriguez, P. Fristrup, A. Riisager, Chem. Eur. J, 2011, 17, 1456-1464.

[20] T.S. Hansen, J. Mielby, A. Riisager, Green Chem. 2011, 13, 109-114.

\section{Suggested text for table of contents}

Harbour not Haber Nitrogen: An amido-substituted furan can be obtained in up to $58 \%$ yield through heating an amino-sugar, which can be obtained from fishery waste, in the presence of $\mathrm{NaCl}$ and boric acid. The product represents a structural motif within biologically active natural products. 


\section{Figure Captions}

Figure 1. a) $\mathrm{N}$-acetyl-D-glucosamine (NAG) and b) 3-acetamido-5-acetylfuran (3A5AF).

Figure 2. Chemical structure of proximicin A.

Figure 3. Normal plot of the effects for 3A5AF production. This plot was produced using Minitab software. Reaction conditions (See Table S1). Figure 4. Effect of adding $\mathrm{NaCl}$ on yield of 3A5AF from NAG supplied by AK Scientific and Alfa Aesar. Solid circles $=$ Alfa Aesar, Hollow circles $=$ AK Scientific . Reaction conditions: 0.2356 g NAG, $0-50 \mathrm{NaCl}$ (mol\% of NAG), $4.5 \mathrm{~mL}$ DMA, ammonia (24.4 mol\% of NAG), MW, $217^{\circ} \mathrm{C}, 15 \mathrm{~min}$.

Figure 5. Effect of added $\mathrm{B}(\mathrm{OH})_{3}, \mathrm{NaCl}$ and $\mathrm{NH}_{3}$ on $3 \mathrm{~A} 5 \mathrm{AF}$ production. Black $=$ NAG from Alfa Aesar. Grey = NAG from AK Scientific. Reaction conditions: 0.2356 g NAG, $4.5 \mathrm{~mL}$ DMA in the presence and absence of $\mathrm{NaCl}$ (30 mol\% with respect to NAG), $\mathrm{NH}_{3}\left(24.4 \mathrm{~mol} \%\right.$ with respect to NAG), 2:1 $\mathrm{B}(\mathrm{OH})_{3}$ : NAG mol ratio, $\mathrm{MW}$, $217^{\circ} \mathrm{C}, 15 \mathrm{~min}$. Yield determined using GC-MS.

Figure 6. Effect of adding different levels of $\mathrm{NaCl}$ at $1: 1 \mathrm{~B}(\mathrm{OH})_{3}: \mathrm{NAG}$ (mol ratio). Reaction conditions: 0.2356 g NAG, 4.5 mL DMA, 10-400 NaCl (mol\% of NAG), 1:1 $\mathrm{B}(\mathrm{OH})_{3}: \mathrm{NAG}$ mol ratio, $\mathrm{MW}, 220^{\circ} \mathrm{C}, 15 \mathrm{~min}$. $3 \mathrm{~A} 5 \mathrm{AF}$ was quantified using GCMS.

Figure 7. Effect of chloride sources on $3 \mathrm{~A} 5 \mathrm{AF}$ production. Reaction conditions: 0.2356 g NAG, $4.5 \mathrm{~mL}$ DMA, 2:1 Cl:NAG mol ratio, 1:1 $\mathrm{B}(\mathrm{OH})_{3}$ :NAG mol ratio, MW, $220^{\circ} \mathrm{C}, 15 \mathrm{~min}$. $3 \mathrm{~A} 5 \mathrm{AF}$ was quantified using GC-MS.

Figure 8. Effect of temperature on $3 \mathrm{~A} 5 \mathrm{AF}$ production. Reaction conditions: 0.2356 g NAG, 4.5 mL DMA, 2:1 NaCl:NAG mol ratio, 1:1 $\mathrm{B}(\mathrm{OH})_{3}: \mathrm{NAG}$ mol ratio, $\mathrm{MW}, 160-250^{\circ} \mathrm{C}, 15 \mathrm{~min}$. Yield was determined using GC-MS.

Figure 9. The optimum reaction conditions for dehydrating NAG into 3A5AF.

Figure 10. Some potential future transformations of 3A5AF. 
Figure 1

a)<smiles>CC(=O)N[C@H]1[C@@H](O)O[C@H](CO)[C@@H](O)[C@H]1O</smiles>

b) $\mathrm{O}$<smiles>CC(=O)Nc1coc(C(C)=O)c1</smiles> 
Figure 2<smiles>COC(=O)Nc1coc(C(=O)Nc2coc(C(N)=O)c2)c1</smiles> 
Figure 3

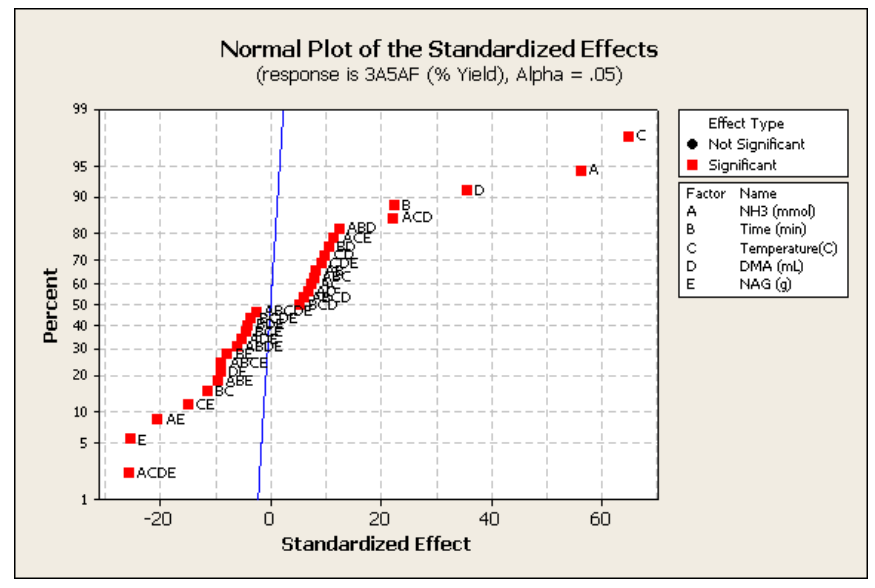


Figure 4

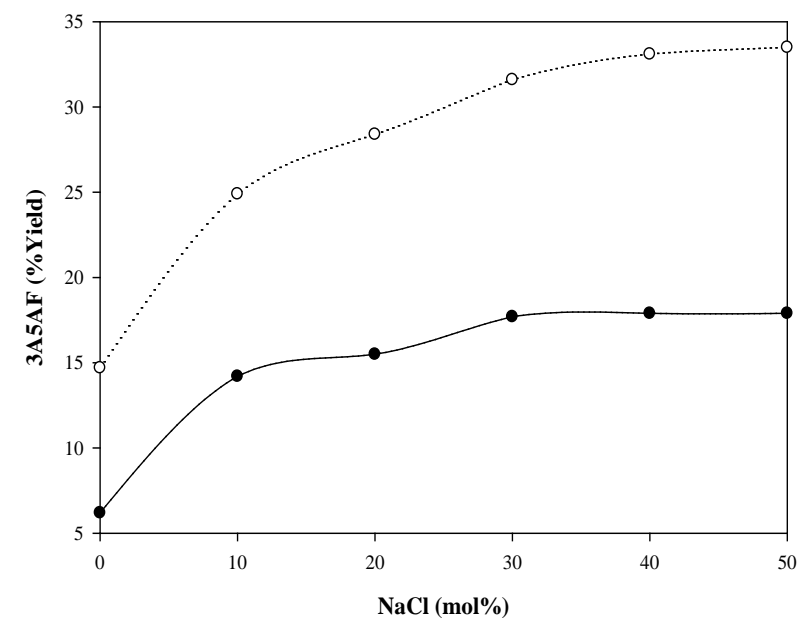


Figure 5

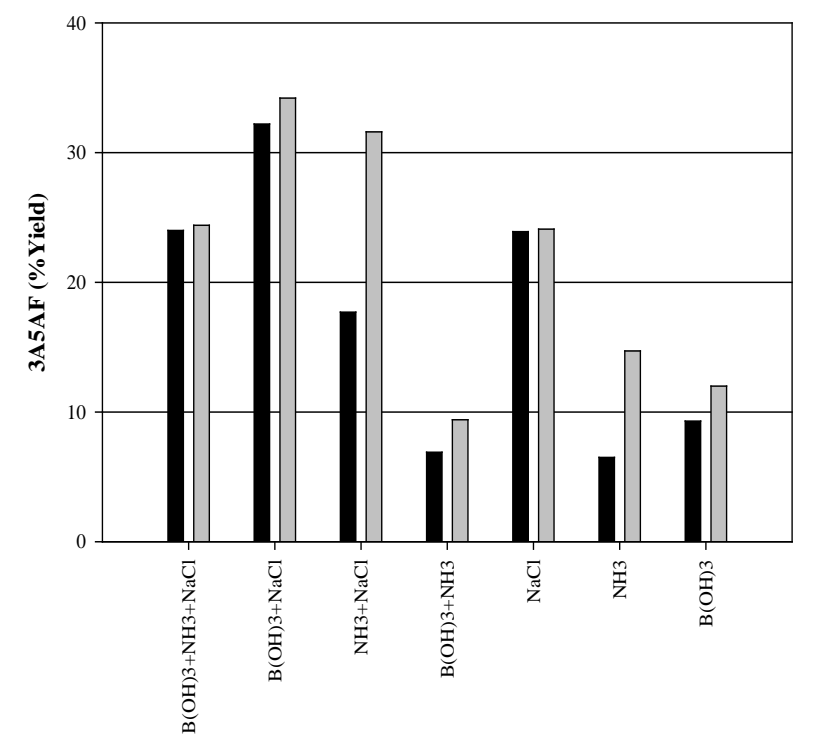


Figure 6

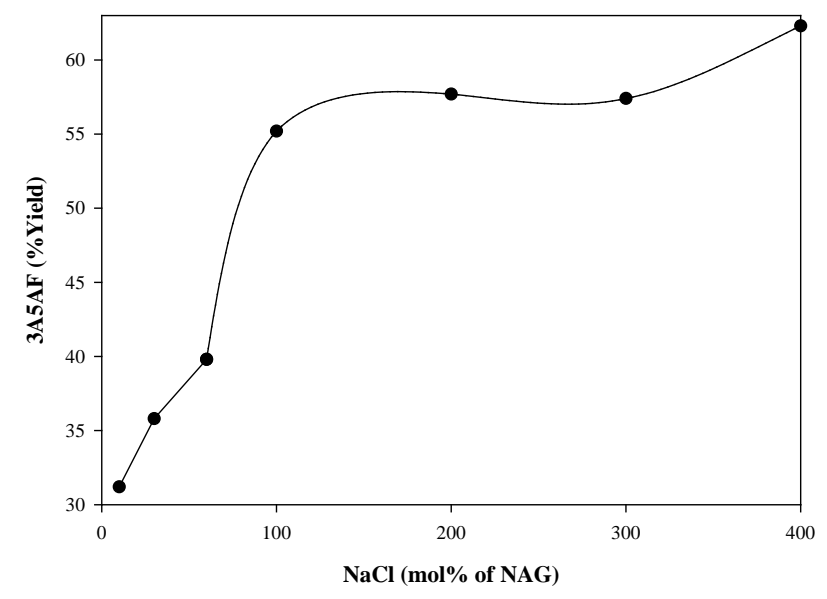


Figure 7

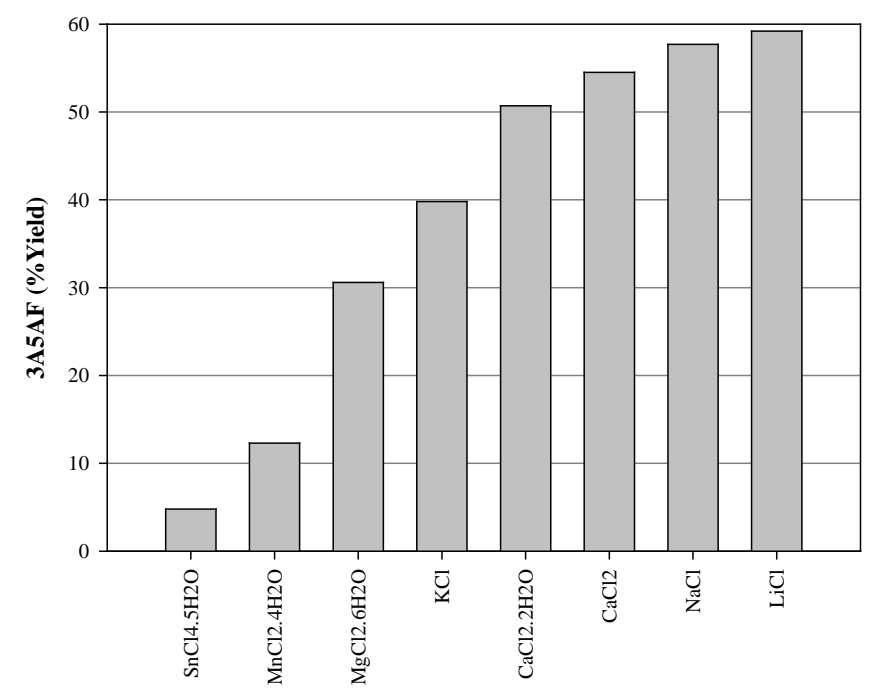


Figure 8

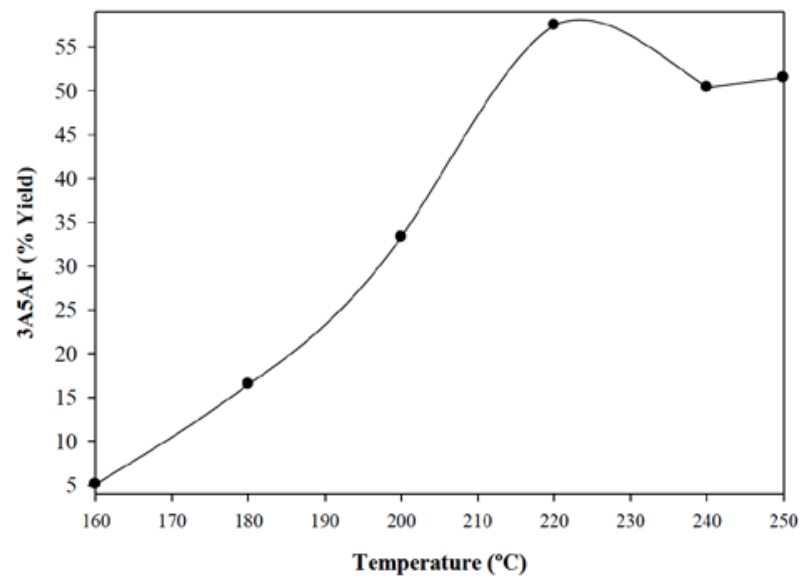


Figure 9

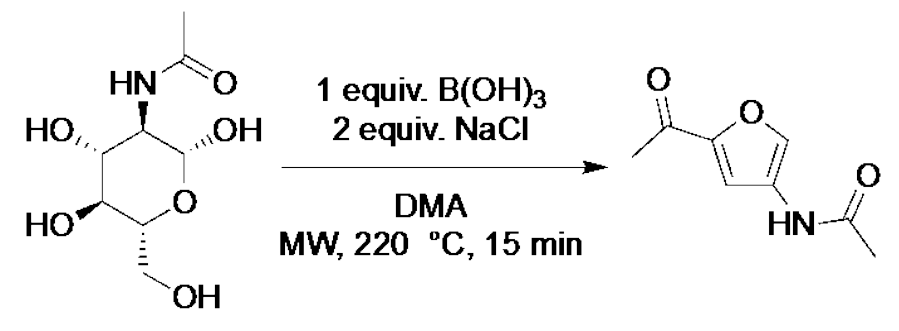


Figure 10

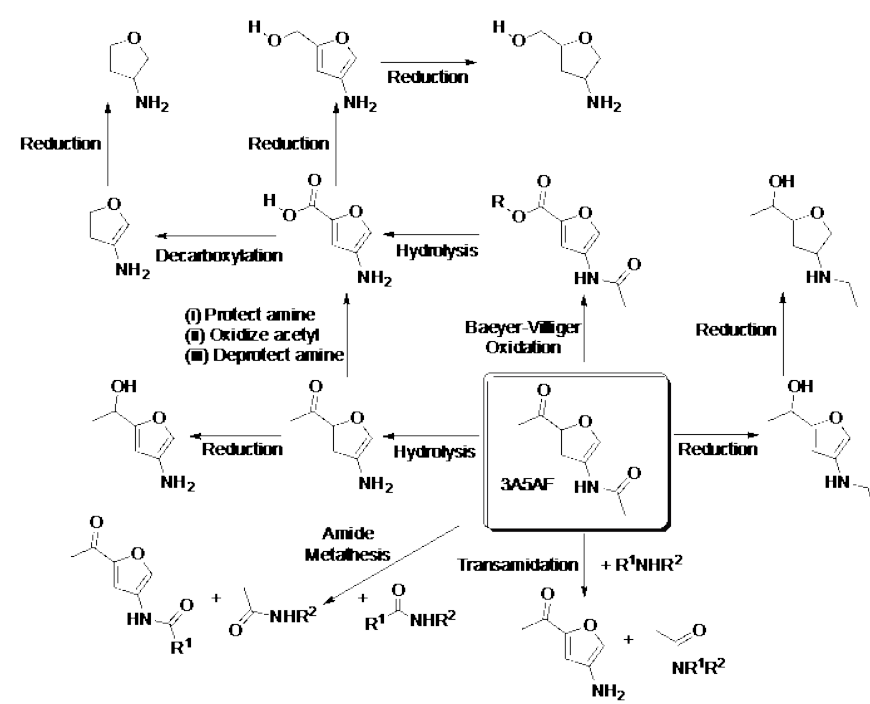


Table of Contents Picture<smiles>CC(=O)N[C@H]1[C@@H](O)O[C@H](CO)[C@@H](O)[C@H]1O</smiles>

N-acetyl-D-glucosamine (NAG)

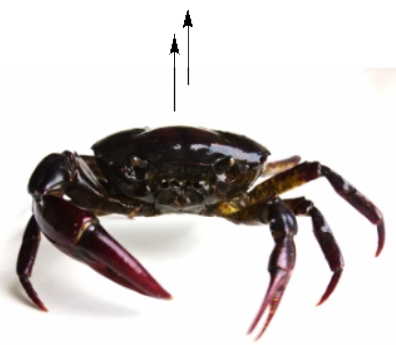

3acetamido-5-acetylfuran (3A5AF)

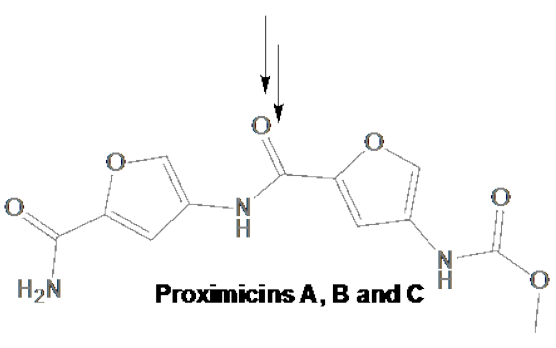

